\title{
A Review of Bimodal Hearing Aid Fitting
}

\author{
Soo Hee Oh \\ Department of Audiology and Speech-Language Pathology, Hallym Univesity of Graduate Studies, Seoul, Korea \\ HUGS Center for Hearing and Speech Research, Seoul, Korea
}

바이모달 보청기 적합 문헌 고찰

오 수 희

한림국제대학원대학교 청각언어치료학과, 한림청각언어연구소

\begin{abstract}
Bimodal hearing refers to the combination of the cochlear implant in one ear and the hearing aid in the opposite ear. Recently, cochlear implant candidacy criteria have been expanded and the number of people receiving cochlear implants with residual hearing has increased, leading to the raised bimodal population. Providing professional fitting services based on systematic bimodal fitting methods or guidelines are essential for the successful bimodal intervention of the hearing impaired. However, there is a lack of evidence-based bimodal fitting method or guideline clinically applicable. In general, bimodal fitting consists of three areas of fitting; cochlear implant mapping, hearing aid fitting, and bimodal fitting. Among them, establishing evidence-based bimodal hearing aid fitting will be a key factor to improve bimodal fitting services of hearing aid centers. The purpose of this study is to review recent literature related to bimodal hearing aid fitting to establish bimodal hearing aid fitting guidelines for hearing aid professionals. This review involves five bimodal hearing aid fitting issues including frequency response, loudness, dynamic compression, frequency transposition, and hearing aid fitting formula. In addition, it described three recent clinical bimodal hearing aid fitting guidelines provided by manufacturers. Two factors contributing to bimodal hearing aid fitting optimization across the studies are frequency response and loudness balance. Conducting loudness balance in bimodal hearing devices and adjusting gains based on the loudness balance tests are one of the important procedures for bimodal fitting optimization. Hearing aid fitting based on wide-band frequency responses and conventional hearing aid formula is recommended for the initial step of the bimodal fitting.
\end{abstract}

Key Words: Bimodal hearing, Bimodal fitting, Loudness balance.

Received: April 2, 2019 / Revised: April 9, 2019 / Accepted: April 9, 2019

Correspondence: Soo Hee Oh, Department of Audiology and Speech-Language Pathology, Hallym Univesity of Graduate Studies, 427 Yeoksam-ro, Gangnam-gu, Seoul 06197, Korea

Tel: +82-70-8680-6901 / Fax: +82-2-3453-6618 / E-mail: osh503@naver.com

\section{INTRODUCTION}

과거 고심도 난청인 경우에만 주로 인공와우 수술을 받았지 만 최근에는 저주파수에 잔존 청력이 남아있는 경우의 인공와 우 수술이 증가하여 인공와우 대상자의 범위가 확대되는 추세 이다(Dowell et al., 2016; Leigh et al., 2016). 저주파수 청력이 남아있는 청각장애인이 한쪽 귀에 보청기를, 반대편 귀에 인공 와우를 착용하는 양이 착용 형태를 말하는 바이모달(bimodal)은 보청기의 음향 자극과 인공와우의 전기 자극이라는 서로

(c) This is an Open Access article distributed under the terms of the Creative Commons Attribution Non-Commercial License (https://creativecommons.org/licenses/by-nc/4.0) which permits unrestricted non-commercial use, distribution, and reproduction in any medium, provided the original work is properly cited.
다른 자극과 서로 다른 두 기기를 통해서 말소리를 이해하는 과정을 거친다. 바이모달 효과를 극대화하기 위해서는 바이모 달 적합이 먼저 최적화되어야 한다. 이때 바이모달 착용자의 양 이 청각기기 간 협응적 조율을 위해 적절한 적합 관리 지침과 방법이 필요하며 이는 성공적인 바이모달 재활에 매우 중요한 요인이 될 수 있다. 바이모달은 보청기를 착용한 귀의 청력을 활 용하여 인공와우의 전기적 신호처리에서 부족한 음향 단서를 보완할 수 있다(Ching et al., 2007; Kong \& Braida, 2011; Kong et al., 2005; McDermott, 2011; Tao et al., 2018). 특히 소음하 말 지각(Dorman et al., 2008), 음악지각(Kong et al., 2005; Sucher $\&$ McDermott, 2009), 하향식 청각인지(Oh et al., 2016), 방향 분별(Gifford \& Dorman, 2018) 등에서 향상을 보였고 이외에 
도 듣기 용이함(Schafer et al., 2011), 사회 활동에서 삶의 질 향상, 청각 정보에의 노출로 인한 언어 발달 촉진, 학업 증진 등 의 효과를 보였다(Nittrouer et al., 2012; Warren \& Dunbar, 2018). 이러한 바이모달 착용 효과는 양이 착용 이득뿐만 아니 라 인공와우에서 처리하지 못하는 말소리의 기본 주파수(fundamental frequency) 또는 시간적 미세구조(temporal fine structure) 말지각 단서의 보완과 전기와 음향 말지각 단서의 통 합 및 상승 효과(Oh et al., 2016; Oh \& Kim, 2014)로 기인될 수 있으며 청각적 단서들의 추출과 통합 과정 모델(Kong \& Braida, 2011)로도 설명된 바 있다. 바이모달 효과 향상을 위해서는 무엇보다도 바이모달 청각기기 적합의 최적화가 선행되어야 하 나, 현재 바이모달 적합에 대한 연구는 많이 부족하여 적절한 적합 방법이 제시되어 있지 않고 증거기반의 체계적인 적합 지 침을 통한 바이모달 중재가 이루어지고 있지 않은 실정이다 (Vroegop et al., 2018). 바이모달 적합 지침 확립을 위해서는 양 귀에 전기와 음향적 특성을 지닌 각각 다른 청각기기 착용에 대 한 이해, 인공와우와 보청기 신호처리의 차이(Francart \& McDermott, 2013), 양귀 간 소리크기 및 주파수 반응의 불균형 등 다양한 요인이 고려되어야 한다.

현재 보청기 또는 인공와우 제조사에서는 임상에서 활용 가 능한 바이모달 적합 권고사항(Advanced Bionics, 2014; Cochlear, 2012; Oticon, 2016)을 제시하였고 바이모달 적합 관련 여러 연구가 진행되고 있다. 그러나 아직까지는 각 청각재활센 터마다 다양한 적합 방법을 적용하는 것으로 나타나(Siburt \& Holmes, 2015) 증거기반의 체계적 바이모달 적합 지침 확립이 필요한 상황이다. 바이모달 적합은 크게 인공와우 적합, 보청기 적합, 바이모달 적합의 세 영역의 적합을 고려해야 한다. 일반 적으로 인공와우 적합이 최적화된 상태에서 보청기 적합 및 양 귀 청각 간 조율과 협응을 위한 바이모달 적합을 진행한다. 현 재 국내 인공와우 적합은 종합병원과 인공와우 시술 병원에서 대부분 시행하고 있으나 바이모달 보청기 적합은 청능재활 또 는 보청기센터에서 수행 가능하며 맞춤형 청각재활의 확대와 함께 앞으로 그 사례가 더 증가할 것으로 예상할 수 있다. 바이 모달 사용자의 체계적인 보청기 적합은 성공적인 바이모달 착 용과 착용 효과 증진에 많은 도움이 될 수 있을 뿐 아니라 적절 한 바이모달 보청기 적합 결과에 따라 향후 바이모달 사용자의 양이 인공와우 시술을 결정하는 중요한 근거가 될 수 있다. 따 라서 적절한 바이모달 중재를 위해서 증거기반의 체계적인 바 이모달 보청기 적합 지침의 확립과 전문가에 의한 최적의 적합 서비스 제공 및 지속적인 관리가 필요하다. 본 연구에서는 바이 모달 보청기 적합에 대한 최근 문헌 고찰을 통하여 바이모달 보청기 적합의 국내 임상적 활용을 재고하고 현재 국내 청능재 활 또는 보청기센터에서 활용 가능한 증거기반의 바이모달 보
청기 적합 근거 마련에 도움이 되고자 한다.

\section{MATERIALS AND METHODS}

\section{바이모달 보청기 적합 관련 연구}

최근 Vroegop et al.(2018)은 체계적 문헌연구를 통해 바이모 달 사용자의 보청기 적합 관련 17 개의 문헌을 분석하였다. 그 결과 바이모달 보청기 적합 시 고려 요인으로 주파수 반응(frequency response), 주파수 전위 또는 압축(frequency transposition of compression), 역동압축(dynamic compression), 음량 (loudness) 4개 영역을 보고하였다. 다음에서는 Vroegop et al. (2018)의 연구를 중심으로 바이모달 보청기 적합 시 고려할 4개 요인과 바이모달 보청기 적합 공식을 포함하여 바이모달 보청 기 적합에 영향을 미칠 수 있는 최근 연구를 살펴보고자 한다.

\section{주파수 반응 관련 연구}

인공와우와 보청기 주파수 영역을 결정하는 것은 바이모달 적합 시 중요한 요인 중 하나이다. 일반적으로 인공와우는 저주 파수에서 고주파 영역(예를 들어, 200 7,500 Hz)까지 주파수 대역을 포함하나 보청기를 착용하는 반대편 귀는 청력에 따라 차이는 있지만 대부분의 경우 저주파수 영역을 포함한다. 이때 인공와우와 보청기 주파수 범위가 중첩되기도 한다(Neuman \& Svirsky, 2013; Vermeire et al., 2008; Zhang et al., 2010). Vroegop et al.(2018)에 따르면 바이모달 보청기 적합 관련 기존 연구에서 크게 두 가지의 보청기 주파수 적합 방법이 시도되었 다. 그중 하나는 대상자의 보청기 착용 귀 청력을 근거로 처방 된 주파수 영역을 증폭 또는 조절하는 방법이며 다른 하나는 보청기로 증폭하고자 하는 주파수 영역을 제한하여 조절하는 방법이다. 이때 주파수 영역 기준은 착용자의 잔존 청력을 기준 으로 하기도 하나 바이모달 주파수 반응과 관련된 여러 연구에 따라 결과의 차이가 있었으며 바이모달 사용자의 주파수 증폭 과 관련된 명확한 기준을 제시하지는 못하였다. 예를 들어 $\mathrm{Da}^{-}$ vidson et al.(2015)에서는 광대역과 제한된 주파수 영역 증폭 적합 시 말지각 결과에서 차이점이 없음을 보고하였다. $\mathrm{Neu}^{-}$ man \& Svirsky(2013)의 경우 광대역 주파수 증폭과 2,000 Hz 주파수 대역까지의 증폭은 더 낮은 주파수 영역으로 제한하여 증폭한 경우보다 향상된 말지각 결과를 보였고 Potts et al. (2009)의 연구에서도 광대역 주파수 적합 시 바이모달 착용으 로 인한 말지각 향상을 보였다. 한편 Messersmith et al.(2015) 은 광대역 주파수 적합의 경우 바이모달 효과를 보이지 않았으 나 2,000 Hz 이상 이득을 감소한 경우 향상된 바이모달 효과 를 보였다. 일반적으로 광대역 주파수 증폭이 제한된 주파수 영역의 증폭과 비교했을 때 바이모달 효과가 비슷하거나 향상 
된 것으로 보고되어 광대역 주파수 증폭을 기본으로 하되, 보 청기의 피드백(feedback) 문제, 소리질 저하, 와우 사영역(dead region)이 존재하는 경우에는 주로 제한된 영역의 주파수 증폭 을 고려하였다(Zhang et al., 2010). 이와 관련하여 Neuman \& Svirsky(2013)와 Zhang et al.(2010)의 연구에서도 잔존 청력의 가장 넓은 주파수 대역을 증폭했을 때 바이모달 효과가 향상됨 을 보고하여 광대역 주파수 증폭의 긍정적 효과를 보고하였다.

\section{주파수 전위 또는 압축 관련 연구}

보청기의 주파수 전위 원리는 원래의 저주파수 소리에 처리된 (전치된) 신호를 추가하는 방법으로 특정 고주파수 소리를 하나 의 저주파수 소리로 이동하는 과정을 포함(Hua et al., 2012)하 며 주파수 압축 시 출력 신호의 주파수 대역폭이 감소된다. 주 파수의 이동은 압축에 의해서 고주파수에서의 에너지 정점 (peak)을 감소시키고 더 낮은 주파수로 낮추는 과정을 거친다 (Davidson et al. 2015; McDermott \& Henshall, 2010; Park et al., 2012; Perreau et al., 2013). 주파수 전위 또는 압축은 바이 모달 사용자의 반대편 귀 보청기를 통한 음향주파수 영역을 증 가시킬 수 있고 이로 인해 고주파수 영역의 청각을 향상시킬 수 있다는 장점이 있다. 주파수 압축을 적용하지 않은 보청기 적합 에서 향상된 결과를 보인 Perreau et al.(2013)을 제외한 4개 연 구(Davidson et al., 2015; Hua et al., 2012; McDermott \& Henshall, 2010; Park et al., 2012)에서 주파수 전위 또는 압축 보청 기 적합과 주파수 전위 또는 압축이 없는 보청기 적합을 비교 했을 때 바이모달 결과에 차이를 보이지 않은 것으로 보고하여 바이모달 상황에서 주파수 전위 또는 압축 효과가 크지 않은 것으로 보여진다.

\section{역동압축 관련 연구}

Veugen et al.(2016a)의 연구에서 보청기의 자동이득장치 (automatic gain control, $\mathrm{AGC)}$ 와 인공와우의 $\mathrm{AGC}$ 조건을 어 느 정도 일치하도록 조절한 뒤 조용한 상황과 단일화자 소음하 에서의 결과를 검사하였다. 보청기의 $\mathrm{AGC}$ 를 느린조건(slow $240 \mathrm{msec}$ 와 1,500 $\mathrm{msec}$ )과 빠른조건(fast 3 과 $80 \mathrm{msec}$ )으로 각각 조절하였고 보청기에서 압축 채널은 인공와우 한 개 채널 의 광대역 압축을 모방하였다. 연구 결과 단일화자 소음하 어 음검사에서 바이모달 사용자의 두 청각기기 간 $\mathrm{AGC}$ 가 유사하 게 조절된 경우 언어인지의 향상을 보였고 말지각과 소리의 질 측면에서 더 높은 주관적 점수를 보고하였다.

\section{음량평형 관련 연구}

보청기와 인공와우 사이의 음량평형은 대부분 바이모달 적 합 연구에서 제시하고 있는 양귀 간 조율과 협응의 핵심 영역
임에도 불구하고 아직까지 음량평형검사 방법은 다양하고 표 준화되지 않았다. Vroegop et al.(2018)에 의하면, 5개 연구에서 양귀 청각기기 간 음량평형 결과는 보청기의 실제적 이득의 변 동에는 거의 영향을 미치지 않으면서도 바이모달 착용 시 언어 인지의 향상을 보인 것으로 보고하였다. 음량평형 방법을 시행 하지 않고 적합을 시행한 경우와 비교했을 때 보청기 이득의 약 3 5 dB 차이를 나타냈으나 Ching et al.(2005)의 연구에서는 보 청기 경험이 없거나 제한적 사용자의 경우 일반적인 보청기 적 합에 근거했을 때보다 약 $7 \mathrm{~dB}$ 이하의 이득이 필요한 것으로 나타났다. 특히 Veugen et al.(2016b)은 각각 다른 음량평형 측 정 방법을 적용하여 비교한 결과 두 개 방법 간의 결과 차이가 없었고 3개 밴드 평형(three-band balancing) 방법이 광대역 평형(broadband balancing) 방법보다 약간 더 낮은 이득을 보 였음을 언급하였다. Keilmann et al.(2009)은 인공와우와 보청 기 각각에 대해 음량평형을 시행한 뒤 인공와우와 보청기의 소 리 크기를 조정하면서 양귀 간 음량평형 측정을 시행하고 바이 모달 효과가 나타날 때까지 평형측정검사를 시행하여 보청기 이득을 조절하기도 하였다.

\section{보청기 적합공식 관련 연구}

바이모달 사용자의 보청기 적합과 관련된 지금까지의 연구에 서 보청기 적합 공식에 따라 언어인지에서 Vroegop et al.(2019a) 은 19명 바이모달 사용자를 대상으로 바이모달 적합 공식인 "Adaptive Phonak Digital Bimodal (APDB)"을 사용하여 적 합한 경우와 일반 보청기 적합공식인 "National Acoustics Laboratory formula-non-linear 2 (NAL-NL2)"를 사용한 경우 조용한 상황과 소음하 상황에서의 말지각을 비교하였다. $\mathrm{APDB}$ 적합공식을 사용한 경우 $2,000 \mathrm{~Hz}$ 이상 이득의 감소와 1,000 $\mathrm{Hz}$ 이상에서 NAL-NL2를 사용한 경우보다 더 높은 압축 비를 보였으나 조용한 상황, 소음하 말지각 및 주관적 설문지에서는 두 적합공식 모두 큰 차이를 보이지 않았다. NAL-NL2와 $\mathrm{Au}^{-}$ diogram+ 적합을 비교한 또 다른 연구에서도(Vroegop et al., 2019b) 두 바이모달 보청기 적합 간 차이가 없음을 보고하였다. Vroegop et al.(2018)의 문헌 연구에서는 Ching et al.(2005)의 연구를 근거로 일반적으로 많이 사용하는 보청기 적합공식인 National Acoustics Laboratory formula-revised profound (NAL-RP), National Acoustics Laboratory formula-non-linear 1 (NAL-NL1), NAL-NL2 또는 Desired Sensation Level (DSL)을 바이모달 아동과 성인의 초기 보청기 적합에 적용하 는 것을 제안하였다.

\section{바이모달 적합지침의 임상적 활용}

현재 보고된 제조사 중심의 바이모달 적합 지침 권고안은 크 
게 다음 세 가지(Advanced Bionics, 2014; Cochlear, 2012; Oticon, 2016)이며 보청기센터에서 직접 활용 가능한 방법과 지침 을 각각 제시하고 있다. 먼저 Advanced Bionics 사는 사전 준 비(calibration), 보청기 적합(hearing aid fitting), 적합 프로그 램 비교(program comparison) 및 음량평형(loudness balancing)의 단계로 바이모달 적합을 제안하고 있으며 특히, 보청기의 주파수 범위를 제한한 경우와 제한하지 않은 경우의 적합을 비 교하고 바이모달 청각기기 간 음량평형을 통한 바이모달 적합의 최적화를 권고하고 있다. 그 내용을 요약하면 Figure 1과 같다.

Oticon 사의 경우 바이모달 적합 시 광대역(wide-band), 주 파수 전위(frequency lowering), 제한된 주파수 대역폭(reduced bandwidth)을 포함하는 3개 주파수 적합의 활용과 선택에 중 점을 두었고 바이모달 청각기기 간의 음량평형과 미세조정 및 바이모달 사용자의 만족도 및 효과를 근거로 주파수 대역을 결 정하는 바이모달 보청기 적합 지침을 제시하였다(Figure 2).

Cochlear 사의 경우 National Acoustic Laboratories의 권고 사항에 따른 바이모달 보청기 적합 방법을 소개하였다. 이때 바이모달 사용자의 어음 이해 향상을 위한 최적의 보청기 주파 수 대역 결정과 보청기와 인공와우 간 양이 소리크기의 평형 측정을 통한 이득 조절을 바이모달 적합 시 고려해야 할 가장
중요한 요인으로 제안하였다. 이를 위해 먼저 NAL-NL1의 보 청기 주파수 반응을 기준으로 $2,000 \mathrm{~Hz}$ 이하 저주파수 반응 을 비교하여 최적의 주파수 반응을 보이는 대역을 결정하였고, 양귀 청각기기 간 음량평형검사를 시행하여 보청기 이득 조절과 양귀 간 음량평형을 이루도록 하였다(Figure 3). 만약 이상의 두 가지 검사를 모두 시행하기 어려운 경우에는 양귀 간 음량평형 측정만이라도 시행할 것을 권고하여 음량평형 측정을 통한 이득 조절의 중요성을 강조하였다. 바이모달 보청기의 미세조정(finetuning)을 위한 선행 절차로 1) 청력역치 측정, 2) NAL 처방의 보 청기 선정, 3) 삽익 이득에 의한 적합 확인, 4) 듣기 편안함을 보 장하기 위한 포화출력음압레벨(output sound pressure level 90)의 확인을 제시하였다. 또한 이러한 보청기 상태에 적응하도 록 사용자는 2-4주간 매일 최소 몇 시간 동안 바이모달 청각기 기를 사용하고 보청기의 미세조절은 인공와우 매핑이 안정된 후 시행하도록 권고하였다. 이외에도 Figure 3에 요약된 주파 수 비교검사 및 음량평형과 관련된 세부 절차, 검사지 및 필요 한 내용을 비교적 자세히 설명, 제공하고 있다.

이상의 세 지침 모두 보청기 주파수 반응의 결정과 음량크기 에서의 균형을 강조한다는 데 그 공통점이 있다. 주파수 반응 결정을 위해서는 기준 주파수(광대역 주파수)와 대안 주파수

Calibration
- Check cochlear implant condition: operating in comfortable level for conversation
- Hearing aid fitting preparation:
1) Verify latest audiogram
2) Verify latest Real Ear to Coupler Difference values
3) Verify acoustical parameters (coupling method, vent size) \& run feedback test
- Hearing aid fitting
- Create two programs
1) Broadband (including prescribed gains at all frequencies)
2) Minimum gains for all frequencies at and above the lowest frequency where the hearing loss exceeds
80 dB HL
- Test real ear measurement
- Select the best sound qualify program in bimodal listening condition while presenting speech at
conversational level (65 dB SPL)
1) Clear preference for the program: select the program as default
2) Not clear preference for the program: perform a sentence test in noise and select a program showing
better performance or select a program after comparing two programs for $2-4$ weeks

Figure 1. A summary of bimodal fitting suggested by Advanced Bionics (Advanced Bionics, 2014). 


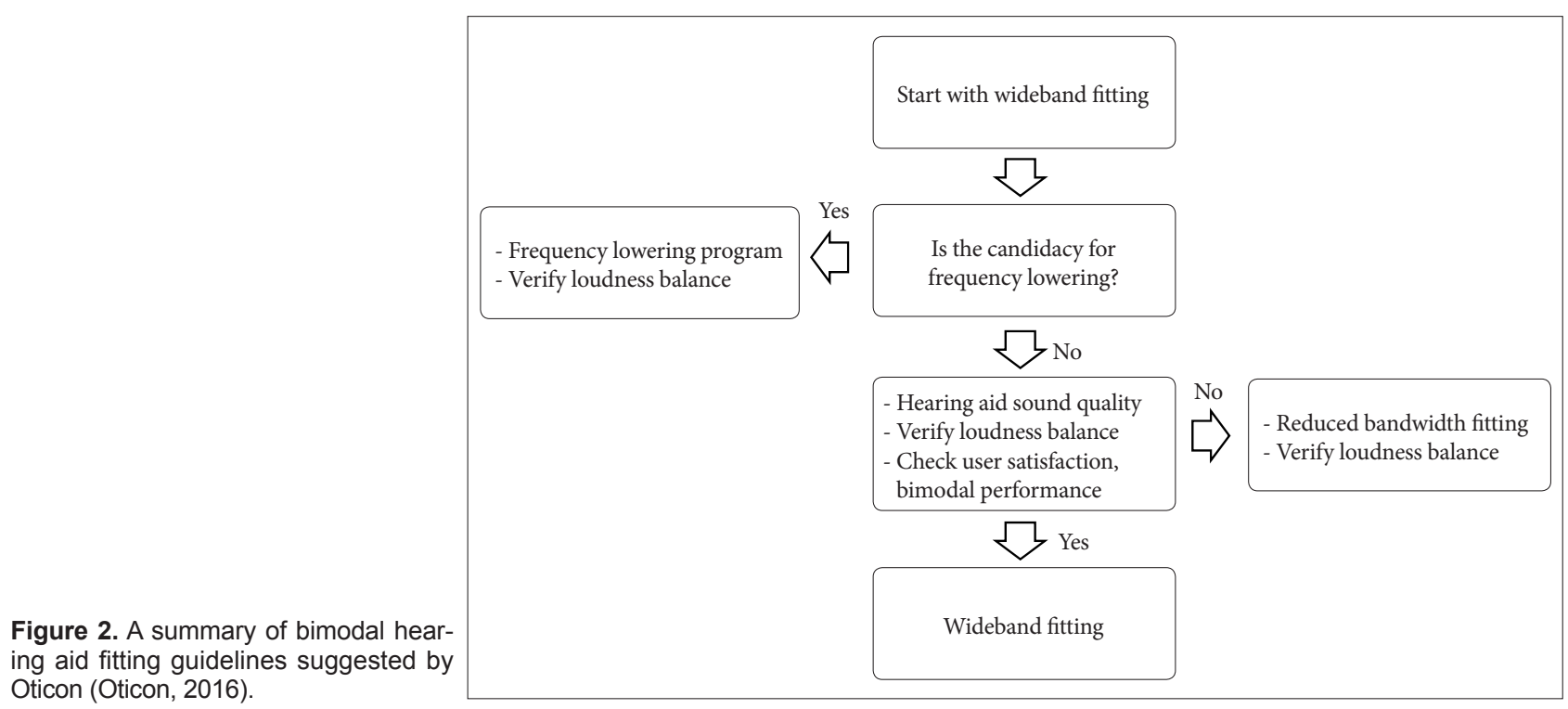

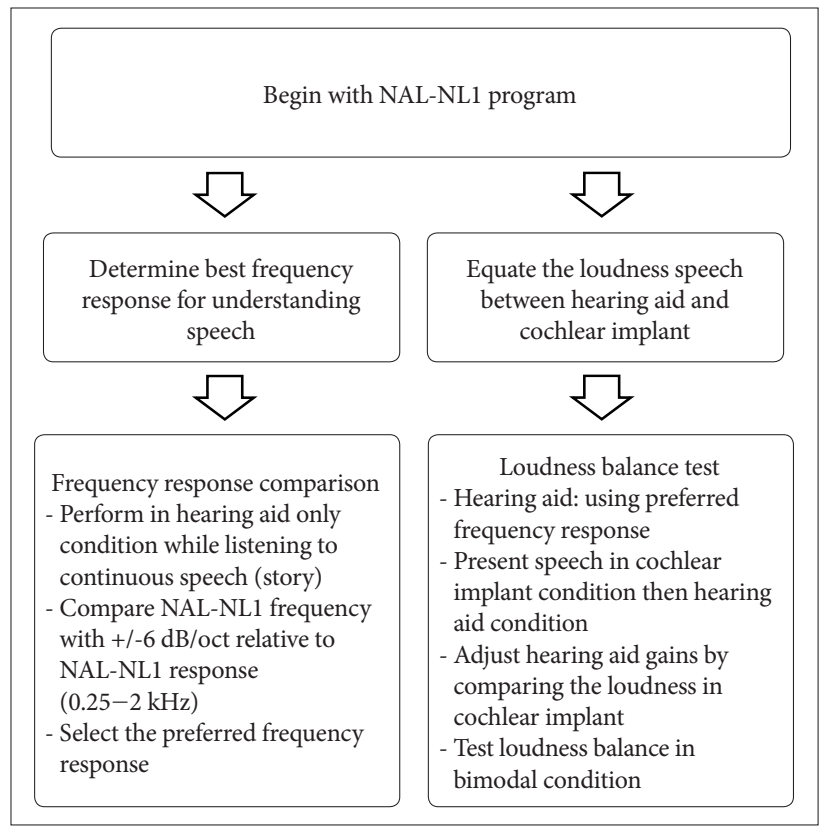

Figure 3. A summary of bimodal fitting suggested by National Acoustic Laboratories (Cochlear, 2012). NAL-NL1: National Acoustics Laboratory formula-non-linear 1, oct: octave.

반응 또는 주파수 압축 등의 프로그램과 비교한 뒤 사용자의 선호도, 어음이해 등의 결과에 따라서 최적의 주파수 반응 프 로그램을 결정하도록 하였다. Oticon 사의 경우 특히 주파수 반응과 관련한 광대역(wide-band), 주파수 전위(frequency lowering), 제한된 주파수 대역폭(reduced bandwidth)의 선택 에 중점을 둔 지침을 제시하였다. 음량평형검사는 인공와우를 통한 음량크기를 기준으로 보청기의 이득을 조절하여 양귀 간 음량평형을 검사하도록 권고하였다.

\section{DISCUSSIONS}

본 문헌고찰에서는 최근 연구를 중심으로 바이모달 보청기 적합에 대한 내용을 살펴보았다. 현재까지 진행된 최근 연구와 적합 지침을 검토한 결과 최적의 보청기 주파수 대역 결정과 양 귀 간 음량평형은 바이모달 보청기 적합 시 우선적으로 고려해 야 할 요인이다. 보청기의 주파수 대역 결정을 위해서 광대역 또 는 제한된 주파수 대역폭에 따른 결과를 비교하거나 사용자가 시험해 볼 수 있도록 하고 사용자의 특별한 선호나 결과의 차 이가 없는 경우 광대역 주파수 반응을 선택하는 것도 임상에 서 활용 가능한 방법일 것이다. 또한 양귀 청각기기 간의 음량 평형을 조율하는 과정은 대부분의 연구 결과 및 지침에서 언급 하고 그 중요성을 강조하고 있다. 보청기 또는 인공와우의 개별 적합과는 다르게 바이모달 사용자는 음향 증폭과 전기 자극의 역동 범위 차이로 인한 양귀 간 소리크기의 불일치(loudness mismatch)가 일어날 수 있으며 이러한 불일치를 최소화하기 위해서 양귀 간 음량평형검사를 시행해서 소리크기를 동일화 하는 것이 중요하다. 음량평형검사 방법은 연구마다 다양하며 아직까지 표준화된 검사 지침은 확립되지 않은 상태이나, 일반 적으로 양귀 청각기기를 착용한 상태에서 또는 순차적으로 착 용한 상태에서 제시되는 어음 소리크기를 비교한 뒤 양귀 간 소리크기의 균형을 이루도록 보청기의 이득을 조절하는 방법 을 사용한다. 이는 국내 청능재활 또는 보청기센터에서도 바이 모달 사용자를 대상으로 활용 가능한 방법이며 국내에서 활용 가능한 구체적인 방법과 지침은 후속 연구에서 제시되어야 할 것이다. 또한 최적의 주파수 반응과 관련하여 보청기 주파수 전 위 또는 압축 방식이 바이모달 효과에 큰 영향을 미치지 않았다 는 연구 결과는 상당히 주목할 사항이다(Vroegop et al., 2018). 
그러나 주파수 반응과 관련하여 바이모달 사용자의 선호도와 선택은 여전히 중요하며 오티콘 사의 경우에도 "frequency lowering" 프로그램을 바이모달 보청기 적합의 선택 사항 중 하 나로 제시할 것을 권고하고 있다. 주파수 전위, 압축과 관련된 바이모달 효과 연구는 향후 좀 더 심도 있게 다루어져야 할 연 구 분야이다. 일반적으로 인공와우의 주파수 범위와 별개로 바 이모달 보청기 적합 시 광대역 주파수 범위를 초기 기준으로 설정할 수 있다. 바이모달 적합에서 보청기 적합공식과 관련된 몇몇 연구가 진행되었으나 각기 다른 보청기 적합공식의 적용 이 바이모달 효과에 큰 영향을 미치는 것으로 보여지지는 않는 다. 특히 바이모달 초기 보청기 적합인 경우 일반적으로 많이 사용하는 NAL 또는 DSL 적합공식을 기본 프로그램으로 사 용하도록 여러 연구에서 제시하고 있다.

바이모달 보청기 적합의 최적화를 위해서는 인공와우 적합 의 최적화가 선행되어야 하며 적절한 바이모달 적합 및 착용 시 기에 대해서도 언급하고 있다(Keilmann et al., 2009; Siburt \& Holmes, 2015). 때로는 인공와우 소리에 적응하기 위해서 인공 와우를 통한 소리 지각이 안정될 때까지 반대편 귀에 보청기를 시간 간격을 두고 순차적으로 착용할 것을 제시하기도 하는데 (Keilmann et al., 2009; Lee, 2005), 이는 인공와우의 전기자 극에 착용자가 잘 적응하고 양귀에 각각 다른 청각기기의 사용 시 조율과 협응을 위한 일시적 과정으로 이해할 수 있다. 또한 일 반적인 보청기 적합과 마찬가지로 바이모달 보청기 적합에서도 보청기 적합 확인은 반드시 필요하며 그 대표적인 방법으로 커플 러 측정과 실이 측정이 있다(Advanced Bionics, 2014; Vroegop et al., 2018). 바이모달 적합 결과는 개인에 따라 차이가 있을 수 있으며(McDermott \& Henshall, 2010; Park et al., 2012), 적합 시 바이모달 사용자의 다양한 청각적 상태, 능력 등을 고려해야 할 것이다. 또한 성인과 아동의 바이모달 적합 방법, 목표 등이 동 일하지 않을 수도 있으며 아동의 나이와 능력에 따라 바이모달 적합 시행에 제약이 따를 수 있다. 그러나 아동의 경우에도 성 인과 마찬가지로 양귀 청각기기의 적절한 청취 상태와 소리크 기의 균형은 바이모달 적합 시 고려해야 할 중요 요인하며 소리 크기에 대한 개념이 부족하고 검사의 세부적 절차를 진행하는 데 협조되지 않는 경우 이에 대한 대안이 필요할 것이다. 한 예 로 아동의 경우 어음에 대한 청각과 시각 자극을 제시하여 청각 자극만을 제시한 경우보다 더 신뢰도 높은 결과를 얻기도 한다.

최적의 바이모달 적합과 관련하여 잔존 청력, 보청기 착용 기 간, 인공와우 착용 효과 등 다양한 고려 요인들이 있다. 이러한 여 러 요인에도 불구하고 바이모달은 말지각, 방향성, 음악지각, 삶의 질 등 여러 영역에서 긍정적인 착용 효과를 보였다. 바이모달 적 합에서 양귀 간 서로 다른 자극의 통합과 균형(Warren \& Dunbar, 2018)을 이루는 것은 중요하며 최적의 바이모달 적합을 위
한 국내 바이모달 적합 지침 관련 연구와 자료가 필요하다. 앞으 로 국내 활용 가능한 체계적인 바이모달 적합 지침이 확립되어 바이모달 착용자의 성공적 재활에 기여할 수 있기를 기대한다.

중심 단어 : 바이모달 청각·바이모달 적합·음량평형.

\section{Ethical Statement N/A}

\section{Acknowledgments}

N/A

\section{Declaration of Conflicting Interests}

There are no conflict interests.

\section{Funding}

N/A

\section{Author Contributions}

S.O. took responsibility for the integrity of the manuscript and contributed to this work by designing and writing the paper, collecting and analyzing data, and revising the manuscript.

\section{ORCID iD}

Soo $\mathrm{Hee} \mathrm{Oh}$

$$
\text { https://orcid.org/0000-0002-3745-1484 }
$$

\section{REFERENCES}

Advanced Bionics. (2014). Bimodal Fitting Quick Guide. Retrieved from http:// www.onici.be/userfiles/files/028-M384-02_Global\%20A4\%20Bimodal\%20Fitting\%20Guidelines\%20for\%20Professionals\%20JUN09_FINAL.pdf.

Ching, T. Y., Hill, M., Brew, J., Incerti, P., Priolo, S., Rushbrook, E., et al. (2005). The effect of auditory experience on speech perception, localization, and functional performance of children who use a cochlear implant and a hearing aid in opposite ears. International Journal of Audiology, 44(12), 677-690.

Ching, T. Y., van Wanrooy, E., \& Dillon, H. (2007). Binaural-bimodal fitting or bilateral implantation for managing severe to profound deafness: A review. Trends in Amplification, 11(3), 161-192.

Cochlear. (2012). Bimodal Hearing. A Guide to Fitting. Retrieved from https:// www.nal.gov.au/wp-content/uploads/sites/2/2017/03/GD3051-CL-Bimodal-Hearing-Brochure-A4-36ppl.pdf.

Davidson, L. S., Firszt, J. B., Brenner, C., \& Cadieux, J. H. (2015). Evaluation of hearing aid frequency response fittings in pediatric and young adult bimodal recipients. Journal of the American Academy of Audiology, 26(4), 393-407.

Dorman, M. F., Gifford, R. H., Spahr, A. J., \& McKarns, S. A. (2008). The benefits of combining acoustic and electric stimulation for the recognition of speech, voice and melodies. Audiology and Neurotology, 13(2), 105-112.

Dowell, R., Galvin, K., \& Cowan, R. (2016). Cochlear implantation: Optimizing outcomes through evidence-based clinical decisions. International Journal of Audiology, 55 Suppl 2, S1-S2.

Francart, T. \& McDermott, H. J. (2013). Psychophysics, fitting, and signal processing for combined hearing aid and cochlear implant stimulation. Ear and Hearing, 34(6), 685-700.

Gifford, R. H. \& Dorman, M. F. (2018, October 3). Bimodal hearing or bilateral cochlear implants? Ask the patient. Ear and Hearing. [Epub ahead of print] https://doi.org/10.1097/AUD.0000000000000657.

Hua, H., Johansson, B., Jönsson, R., \& Magnusson, L. (2012). Cochlear implant combined with a linear frequency transposing hearing aid. Jour- 
nal of the American Academy of Audiology, 23(9), 722-732.

Keilmann, A. M., Bohnert, A. M., Gosepath, J., \& Mann, W. J. (2009). Cochlear implant and hearing aid: A new approach to optimizing the fitting in this bimodal situation. European Archives of Oto-Rhino-Laryngology, 266(12), 1879-1884.

Kong, Y. Y. \& Braida, L. D. (2011). Cross-frequency integration for consonant and vowel identification in bimodal hearing. Journal of Speech, Language, and Hearing Research, 54(3), 959-980.

Kong, Y. Y., Stickney, G. S., \& Zeng, F. G. (2005). Speech and melody recognition in binaurally combined acoustic and electric hearing. The Journal of the Acoustical Society of America, 117(3 Pt 1), 1351-1361.

Lee, J. H. (2005). Bimodal fitting with a cochlear implant and a hearing aid in the opposite ear. Audiology and Speech Research, 1(1), 14-18.

Leigh, J. R., Moran, M., Hollow, R., \& Dowell, R. C. (2016). Evidence-based guidelines for recommending cochlear implantation for postlingually deafened adults. International Journal of Audiology, 55 Suppl 2, S3-S8.

McDermott, H. (2011). Benefits of combined acoustic and electric hearing for music and pitch perception. Seminars in Hearing, 32(1), 103-114.

McDermott, H. \& Henshall, K. (2010). The use of frequency compression by cochlear implant recipients with postoperative acoustic hearing. Journal of the American Academy of Audiology, 21(6), 380-389.

Messersmith, J. J., Jorgensen, L. E., \& Hagg, J. A. (2015). Reduction in highfrequency hearing aid gain can improve performance in patients with contralateral cochlear implant: A pilot study. American Journal of Audiology, 24(4), 462-468.

Neuman, A. C. \& Svirsky, M. A. (2013). Effect of hearing aid bandwidth on speech recognition performance of listeners using a cochlear implant and contralateral hearing aid (bimodal hearing). Ear and Hearing, 34(5), 553-561.

Nittrouer, S., Caldwell, A., Lowenstein, J. H., Tarr, E., \& Holloman, C. (2012). Emergent literacy in kindergartners with cochlear implants. Ear and Hearing, 33(6), 683-697.

Oh, S. H., Donaldson, G. S., \& Kong, Y. Y. (2016). Top-down processes in simulated electric-acoustic hearing: The effect of linguistic context on bimodal benefit for temporally interrupted speech. Ear and Hearing, 37(5), 582-592.

Oh, S. H. \& Kim, J. S. (2014). Speech perception and benefits from the contralateral device of cochlear implant users: A review of recent literature. Audiology and Speech Research, 10(2), 87-98.

Oticon. (2016). Bimodal Hearing Aid Fitting Guidelines. Retrieved from https:// www.oticon.nl/-/media/oticon/main/pdf/master/bimodal/22596uk_ wp_bimodal_fitting_h2_2016.pdf?la=nl-nl.

Park, L. R., Teagle, H. F., Buss, E., Roush, P. A., \& Buchman, C. A. (2012). Effects of frequency compression hearing aids for unilaterally implanted children with acoustically amplified residual hearing in the nonimplanted ear. Ear and Hearing, 33(4), el-e12.

Perreau, A. E., Bentler, R. A., \& Tyler, R. S. (2013). The contribution of a frequency-compression hearing aid to contralateral cochlear implant per- formance. Journal of the American Academy of Audiology, 24(2), 105120 .

Potts, L. G., Skinner, M. W., Litovsky, R. A., Strube, M. J., \& Kuk, F. (2009). Recognition and localization of speech by adult cochlear implant recipients wearing a digital hearing aid in the nonimplanted ear (bimodal hearing). Journal of the American Academy of Audiology, 20(6), 353-373.

Schafer, E. C., Amlani, A. M., Paiva, D., Nozari, L., \& Verret, S. (2011). A meta-analysis to compare speech recognition in noise with bilateral cochlear implants and bimodal stimulation. International Journal of Audiology, 50(12), 871-880.

Siburt, H. W. \& Holmes, A. E. (2015). Bimodal programming: A survey of current clinical practice. American Journal of Audiology, 24(2), 243249.

Sucher, C. M. \& McDermott, H. J. (2009). Bimodal stimulation: Benefits for music perception and sound quality. Cochlear Implants International, 10 Suppl 1, 96-99.

Tao, D. D., Liu, J. S., Yang, Z. D., Wilson, B. S., \& Zhou, N. (2018, February 16). Bilaterally combined electric and acoustic hearing in Mandarinspeaking listeners: The population with poor residual hearing. Trends in Hearing. [epub] https://doi.org/10.1177/2331216518757892.

Vermeire, K., Anderson, I., Flynn, M., \& Van de Heyning, P. (2008). The influence of different speech processor and hearing aid settings on speech perception outcomes in electric acoustic stimulation patients. Ear and Hearing, 29(1), 76-86.

Veugen, L. C., Chalupper, J., Snik, A. F., Opstal, A. J., \& Mens, L. H. (2016a). Matching automatic gain control across devices in bimodal cochlear implant users. Ear and Hearing, 37(3), 260-270.

Veugen, L. C., Chalupper, J., Snik, A. F., van Opstal, A. J., \& Mens, L. H. (2016b). Frequency-dependent loudness balancing in bimodal cochlear implant users. Acta Oto-Laryngologica, 136(8), 775-781.

Vroegop, J. L., Goedegebure, A., \& van der Schroeff, M. P. (2018). How to optimally fit a hearing aid for bimodal cochlear implant users: A systematic review. Ear and Hearing, 39(6), 1039-1045.

Vroegop, J. L., Homans, N. C., van der Schroeff, M. P., \& Goedegebure, A. (2019a). Comparing two hearing aid fitting algorithms for bimodal cochlear implant users. Ear and Hearing, 40(1), 98-106.

Vroegop, J. L., Dingemanse, J. G., van der Schroeff, M. P., \& Goedegebure, A. (2019b). Comparing the effect of different hearing aid fitting methods in bimodal cochlear implant users. American Journal of Audiology, 28(1), 1-10

Warren, S. E. \& Dunbar, M. N. (2018). Bimodal hearing in individuals with severe-to-profound hearing loss: Benefits, challenges, and management. Seminars in Hearing, 39(4), 405-413.

Zhang, T., Dorman, M. F., \& Spahr, A. J. (2010). Information from the voice fundamental frequency (F0) region accounts for the majority of the benefit when acoustic stimulation is added to electric stimulation. Ear and Hearing, 31(1), 63-69. 